\title{
Hydrogen Bonding Interaction between Atmospheric Gaseous Amides and Methanol
}

\author{
Hailiang Zhao ${ }^{1}$, Shanshan Tang ${ }^{1}$, Xiang $\mathrm{Xu}^{2}$ and Lin $\mathrm{Du}{ }^{1, *}$ \\ 1 Environment Research Institute, Shandong University, Shanda South Road 27, Jinan 250100, Shandong, \\ China; zhaoh10211@sina.com (H.Z.); tangshanshan9210@sina.com (S.T.) \\ 2 College of Chemistry and Pharmaceutical Sciences, Qingdao Agricultural University, Changcheng Road 700, \\ Qingdao 266109, Shandong, China; xuxiang2016@sina.cn \\ * Correspondence: lindu@sdu.edu.cn; Tel./Fax: +86-531-8836-6072
}

Academic Editor: Mihai V. Putz

Received: 29 September 2016; Accepted: 12 December 2016; Published: 30 December 2016

\begin{abstract}
Amides are important atmospheric organic-nitrogen compounds. Hydrogen bonded complexes of methanol $(\mathrm{MeOH})$ with amides (formamide, $N$-methylformamide, $\mathrm{N}, \mathrm{N}$-dimethylformamide, acetamide, $\mathrm{N}$-methylacetamide and $\mathrm{N}, \mathrm{N}$-dimethylacetamide) have been investigated. The carbonyl oxygen of the amides behaves as a hydrogen bond acceptor and the $\mathrm{NH}$ group of the amides acts as a hydrogen bond donor. The dominant hydrogen bonding interaction occurs between the carbonyl oxygen and the $\mathrm{OH}$ group of methanol as well as the interaction between the NH group of amides and the oxygen of methanol. However, the hydrogen bonds between the $\mathrm{CH}$ group and the carbonyl oxygen or the oxygen of methanol are also important for the overall stability of the complexes. Comparable red shifts of the $\mathrm{C}=\mathrm{O}, \mathrm{NH}$ - and $\mathrm{OH}$-stretching transitions were found in these $\mathrm{MeOH}$-amide complexes with considerable intensity enhancement. Topological analysis shows that the electron density at the bond critical points of the complexes fall in the range of hydrogen bonding criteria, and the Laplacian of charge density of the $\mathrm{O}-\mathrm{H} \cdots \mathrm{O}$ hydrogen bond slightly exceeds the upper value of the Laplacian criteria. The energy decomposition analysis further suggests that the hydrogen bonding interaction energies can be mainly attributed to the electrostatic, exchange and dispersion components.
\end{abstract}

Keywords: hydrogen bond; molecular complexes; energy decomposition analysis

\section{Introduction}

Amides have attracted great attention due to their importance to $\mathrm{N}-\mathrm{H} \cdots \mathrm{O}$ hydrogen bonding interaction in determining the structures and properties of biological systems, such as the interactions between protein and polypeptides [1-3]. Amide is a simplified example of peptide linkage, which allows studying both hydrophobic and hydrophilic interactions. On the other hand, amides have been widely observed in the atmosphere [4]. Amides are emitted from a variety of natural and anthropogenic sources including agriculture, biomass burning, animal husbandry, cooking, synthetic leather, carbon capture, and other industrial processes [4-6]. For example, formamide (FA, $\left.\mathrm{HC}(\mathrm{O}) \mathrm{NH}_{2}\right)$ is a high production volume chemical (HPV) with an annual global production of several hundred thousand tons [7]. FA was detected in the emissions from an industrial carbon capture facility via degradation of mono-ethanolamine, using proton transfer reaction time-of-flight mass spectrometry (PTR-ToF-MS) [5]. $\mathrm{N}, \mathrm{N}$-dimethylformamide (DMF) was observed near a municipal incinerator, waste collection center and sewage treatment plant with a concentration of 1.2-14.2 $\mu \mathrm{g} \cdot \mathrm{m}^{-3}$ [8]. Moreover, amides can also be formed by the degradation of amines [6]. Amide in the atmosphere can react with $\mathrm{OH}$ radicals, and lead to gaseous degradation products and formation of secondary organic aerosols $[7,9]$. 
New particle formation (NPF) is an important mechanism to form atmospheric aerosols [10]. NPF has been estimated to account for roughly half the global budget of the atmosphere's cloud condensation nuclei (CCN), which influences cloud properties and Earth's energy balance [11]. At the molecular level, molecular complexes and pre-nucleation clusters are at the initial stage of NPF whose strength determines the thermodynamic stability of these complexes. Hydrogen bonding interaction is one of the driving forces for the formation of atmospheric molecular complexes. The composition in the initial nucleation clusters is very critical [12-15], but the species involved in the atmospheric nucleation are still largely unknown [16,17]. It is well known that trace atmospheric organic species other than $\mathrm{H}_{2} \mathrm{SO}_{4}$ and $\mathrm{H}_{2} \mathrm{O}$ are involved in nucleation [18]. Atmospheric methanol $(\mathrm{MeOH})$ is one of the most abundant organic compounds in the atmosphere $[12,19,20]$. Fifty percent of the measured oxygenated volatile organic compounds (OVOCs) in Zürich were alcohols [20]. Furthermore, $11.9 \%$ of the top 20 OVOC (by mass) emissions from anthropogenic sources (in the UK) in 2010 was $\mathrm{MeOH}$ [19]. Due to the importance of $\mathrm{MeOH}$ in the atmosphere, many studies have been carried out to investigate the initial stages of the atmospheric aerosol nucleation involving $\mathrm{MeOH}$ [21]. A matrix isolation spectroscopic method and theoretical studies were carried out to investigate the hydrogen bonding in the $\mathrm{H}_{2} \mathrm{SO}_{4} / \mathrm{MeOH} / \mathrm{H}_{2} \mathrm{O}$ system [21]. The results revealed that the observed complexes may be precursors in the atmospheric sulfate and bisulfate cluster formation. Amine is an important compound for atmospheric nucleation [22,23]. Fourier transform infrared (FTIR) and density functional theory (DFT) studies have been carried out for the interactions between $\mathrm{MeOH}$ and dimethylamine/trimethylamine complexes [24]. The IR spectrum shows a characteristic red shift of the $\mathrm{OH}$-stretching vibrational band of 301 and $333 \mathrm{~cm}^{-1}$ for $\mathrm{MeOH}$-dimethylamine and $\mathrm{MeOH}$-trimethylamine, respectively. The calculated binding energies for these two complexes were about $-25 \sim-27 \mathrm{~kJ} \cdot \mathrm{mol}^{-1}$ (B3LYP/aug-cc-pVTZ).

The impact of the molecular interactions between $\mathrm{MeOH}$ and amides in atmospheric clustering has been investigated in the present study. Theoretical calculations of complexes consisting of $\mathrm{MeOH}$ and the atmospheric common amides (formamide (FA), $\mathrm{N}$-methylformamide (NMF), $\mathrm{N}, \mathrm{N}$-dimethylformamide (DMF), acetamide (AA), $\mathrm{N}$-methylacetamide (NMA) and $\mathrm{N}, \mathrm{N}$-dimethylacetamide (DMA)) were carried out to determine the geometric parameters, binding energies and Gibbs free energies of formation. Atoms in molecules (AIM) analysis was used to investigate the electronic densities and the inter-molecular hydrogen bonding interactions in the complexes [25,26]. Generalized Kohn-Sham energy decomposition analysis (GKS-EDA) was performed to study the contribution of different components to total interaction energy [27].

\section{Results and Discussion}

\subsection{Geometric Analysis}

The optimized structures of the amide monomers at the B3LYP-D3/aug-cc-pVTZ level are shown in Figure 1. Both NMF and NMA have two isomers, where cis and trans refer to the orientation of the $\mathrm{C}=\mathrm{O}$ and $\mathrm{N}-\mathrm{H}$ bonds with respect to the $\mathrm{C}-\mathrm{N}$ bond. Previous studies demonstrated that the trans-form was more stable in the gas phase [28-30], which is consistent with our study: trans-NMF > cis-NMF by $4.8 \mathrm{~kJ} \cdot \mathrm{mol}^{-1}$ (B3LYP-D3/aug-cc-pVTZ, corrected with ZPVE) and trans-NMA > cis-NMA by $9.7 \mathrm{~kJ} \cdot \mathrm{mol}^{-1}$ (B3LYP-D3/aug-cc-pVTZ, corrected with ZPVE).

Several orientations of $\mathrm{MeOH}$ with respect to the carbonyl oxygen were examined. There are two possible types of hydrogen bonding interactions in the complexes, $\mathrm{O}-\mathrm{H} \cdots \mathrm{O}=\mathrm{C}$ and $\mathrm{N}-\mathrm{H} \cdots \mathrm{O}$. The $\mathrm{MeOH}$-amide (A) structures (Figures 2 and 3) are the ones in which $\mathrm{MeOH}$ approaches the carbonyl oxygen from the opposite side of the $\mathrm{N}$ atom. The main interaction occurs between the $\mathrm{OH}$ group of $\mathrm{MeOH}$ and the carbonyl oxygen of the amides to form the $\mathrm{O}-\mathrm{H} \cdots \mathrm{O}=\mathrm{C}$ hydrogen bonds. When $\mathrm{MeOH}$ moves towards the carbonyl oxygen from the same side of nitrogen, the structure is noted as (B) in Figures 2 and 3. Interestingly, the MeOH-FA (B), MeOH-AA (B), MeOH-cis-NMF (B), MeOH-cis-NMA (B) complexes form six-membered cyclic ring structures via the $\mathrm{O}-\mathrm{H} \cdots \mathrm{O}=\mathrm{C}$ and $\mathrm{N}-\mathrm{H} \cdots \mathrm{O}$ hydrogen 
bonds. Meanwhile, the NH groups in AA, FA, trans-NMA and trans-NMF act as hydrogen bond donors while $\mathrm{MeOH}$ is the hydrogen bond acceptor to form $\mathrm{N}-\mathrm{H} \cdots \mathrm{O}$ hydrogen bonded complexes, and they are noted as amide- $\mathrm{MeOH}$. Amide nitrogen is generally a poor nucleophile because of the amide resonance. The conjugation with the electron-withdrawing carbonyl group reduces the electron density of the nitrogen atom. In addition, the steric hindrance between terminal methyl groups also prevents the $\mathrm{N}$ atom from being a proton acceptor.

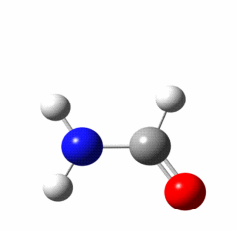

FA

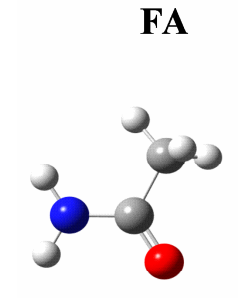

AA

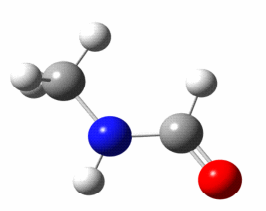

trans-NMF

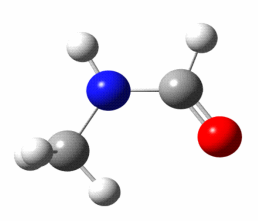

cis-NMF

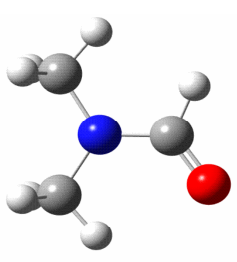

DMF

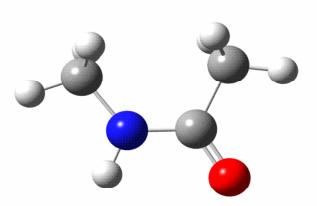

trans-NMA

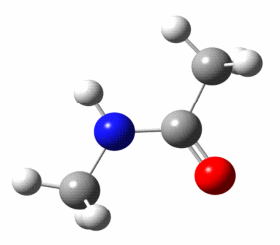

cis-NMA

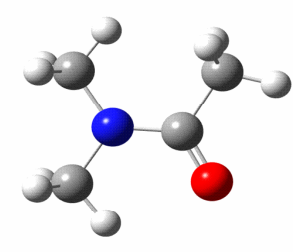

DMA

Figure 1. The stable structures of the monomers obtained at the B3LYP-D3/aug-cc-pVTZ level; FA: formamide; NMF: $N$-methylformamide; DMF: $N, N$-dimethylformamide; AA: acetamide; NMA: $N$-methylacetamide; DMA: $N, N$-dimethylacetamide.

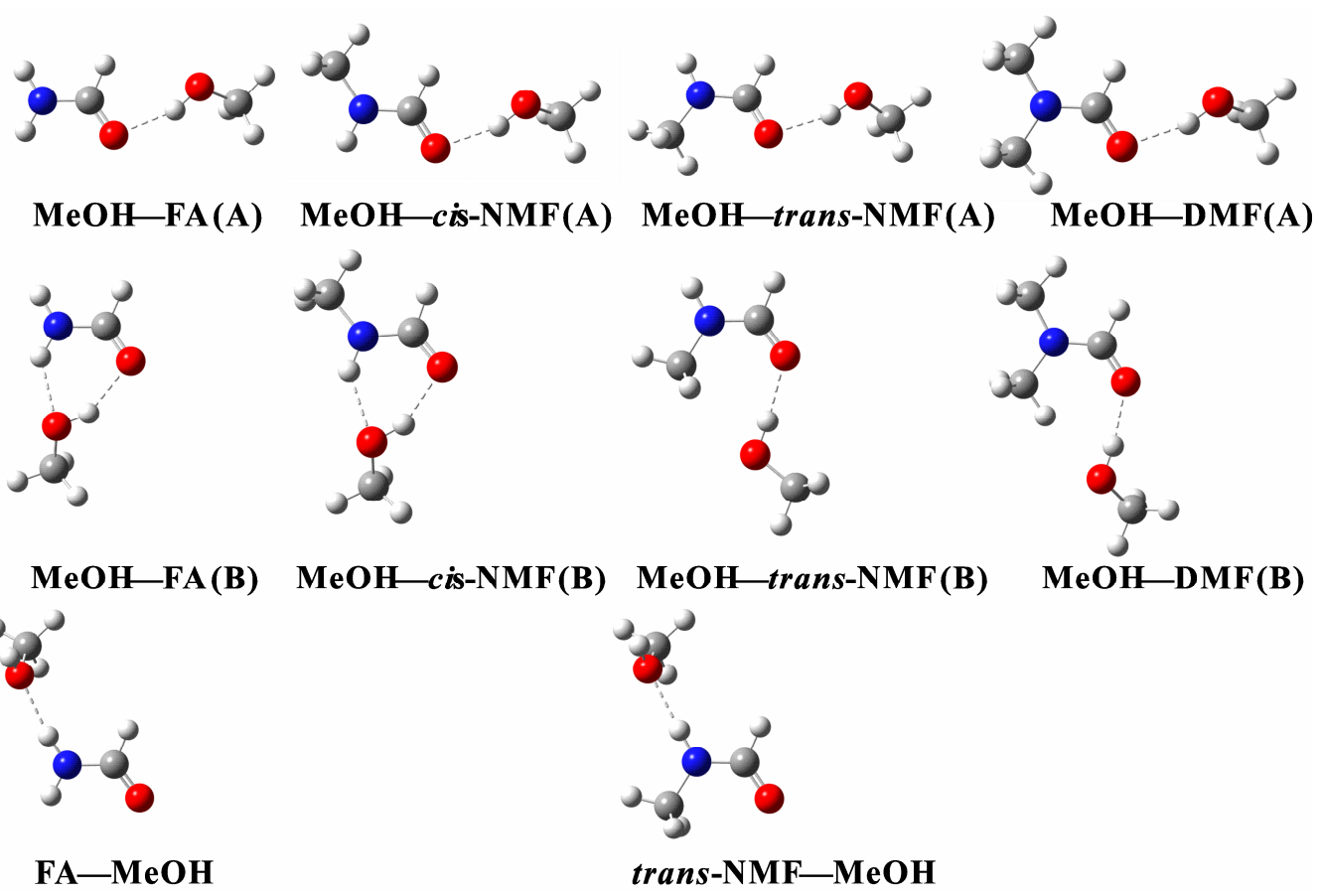

Figure 2. The stable structures of the $\mathrm{MeOH}$-formamide and formamide-MeOH complexes obtained at the B3LYP-D3/aug-cc-pVTZ level; The O-H $\cdots \mathrm{O}$ and $\mathrm{N}-\mathrm{H} \cdots \mathrm{O}$ hydrogen bonds are presented by the dotted lines; FA: formamide; NMF: $N$-methylformamide; DMF: $N, N$-dimethylformamide; MeOH: methanol. 


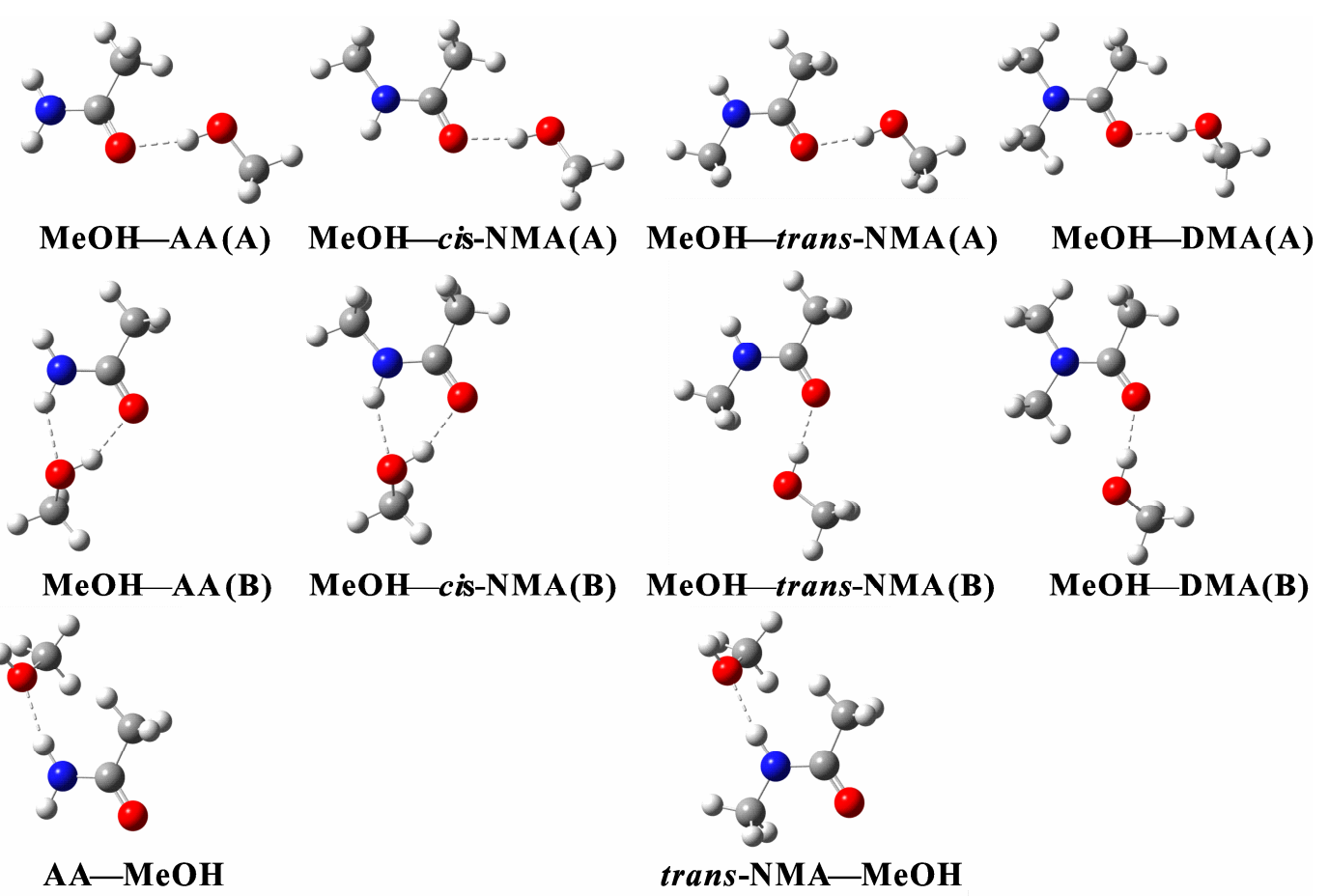

Figure 3. The stable structures of the $\mathrm{MeOH}$-acetamide and acetamide- $\mathrm{MeOH}$ complexes obtained at the B3LYP-D3/aug-cc-pVTZ level; The O-H $\cdots \mathrm{O}$ and $\mathrm{N}-\mathrm{H} \cdots \mathrm{O}$ hydrogen bonds are presented by the dotted lines; AA: acetamide; NMA: $N$-methylacetamide; DMA: $N, N$-dimethylacetamide; $\mathrm{MeOH}$ : methanol.

Selected geometric parameters obtained at the B3LYP-D3/aug-cc-pVTZ level are listed in Table 1. The interactions between $\mathrm{MeOH}$ and amide are called resonance-assisted hydrogen bonding (RAHB), where they involve a category of homo-nuclear hydrogen bonds $(-\mathrm{O}-\mathrm{H} \cdots \mathrm{O}=)$ where two oxygen atoms are inter-connected by a system of $\pi$-conjugated double bonds [31-34]. The contact distance $d(\mathrm{O}-\mathrm{O})$ between the two oxygen atoms in the hydrogen bond $(-\mathrm{O}-\mathrm{H} \cdots \mathrm{O}=)$ has been employed as an indicator of the hydrogen bond strength [31]. The contact distances in the $\mathrm{MeOH}$-amide (A) and (B) structures are in the range of $2.76-2.83 \AA$, and belong to medium or weak hydrogen bonds.

Proton transfer may occur between interacting molecules which leads to additional cluster stabilization. An ion pair can be formed via proton transfer from an acid moiety (e.g., $\mathrm{H}_{2} \mathrm{SO}_{4}$ ) to a base moiety (e.g., $\mathrm{NH}_{3}$, amine). In the $\mathrm{H}_{2} \mathrm{SO}_{4}$-DMA complex, the $\mathrm{OH}$ bond of $\mathrm{H}_{2} \mathrm{SO}_{4}$ was elongated by $0.710 \AA$ (PW91PW91/6-311++G(2d, 2p)) upon complexation [35]. Due to the higher proton affinity of amines, the proton was transferred from oxygen in $\mathrm{H}_{2} \mathrm{SO}_{4}$ to nitrogen in DMA. However, proton transfer did not occur in succinic acid-DMA- $\left(\mathrm{H}_{2} \mathrm{O}\right)_{0-3}$, where the $\mathrm{OH}$ bond lengths were only elongated by 0.108-0.244 $\AA$ (PW91PW91/6-311++G(2d, 2p)) [35]. In this study, the changes in the OH bond length of $\mathrm{MeOH}$ upon complexation $(\Delta \mathrm{r}(\mathrm{OH})$ in Table 1) vary from 0.010 to $0.017 \AA$ in the $\mathrm{MeOH}$-amide (A) and (B) complexes, however, the changes in the $\mathrm{NH}$ bond length of amides upon complexation $(\Delta \mathrm{r}(\mathrm{NH})$ in Table 1$)$ are much smaller $(<0.009 \AA)$ in the $\mathrm{MeOH}$-amide $(\mathrm{B})$ and amide-MeOH complexes. The relative small changes of the $\mathrm{OH}$ or $\mathrm{NH}$ bond upon complexation clearly reveal that there is no proton transfer in the hydrogen bonding interactions between $\mathrm{MeOH}$ and amides. 
Table 1. Selected optimized geometric parameters in the $\mathrm{O}-\mathrm{H} \cdots \mathrm{O}, \mathrm{N}-\mathrm{H} \cdots \mathrm{O}$ and $\mathrm{C}=\mathrm{O}$ of the hydrogen bonded $\mathrm{MeOH}-$ amide and amide-MeOH complexes at the B3LYP-D3/aug-cc-pVTZ level (angles in degrees; lengths/distances in $\AA$ ).

\begin{tabular}{|c|c|c|c|c|c|c|c|c|c|}
\hline \multirow{2}{*}{ Type } & \multirow{2}{*}{ Conformer } & \multicolumn{4}{|c|}{$\mathrm{O}-\mathrm{H} \cdots \mathrm{O}$} & \multicolumn{3}{|c|}{$\mathrm{N}-\mathrm{H} \cdots \mathrm{O}$} & \multirow{2}{*}{$\begin{array}{c}\mathrm{C}=\mathrm{O} \\
\Delta \mathrm{r}(\mathrm{C}=\mathrm{O}) \mathrm{f}\end{array}$} \\
\hline & & $\Delta \mathrm{r}(\mathrm{OH})^{\mathrm{a}}$ & $\mathbf{r}(\mathrm{HB})^{b}$ & $\theta(\mathrm{HB})^{c}$ & $d(O-O)^{d}$ & $\Delta \mathrm{r}(\mathrm{NH}){ }^{\mathrm{e}}$ & $\mathbf{r}(\mathrm{HB})^{b}$ & $\theta(\mathrm{HB})^{c}$ & \\
\hline \multirow{8}{*}{ MeOH-amide (A) } & FA & 0.0102 & 1.8940 & 158.3 & 2.8193 & - & - & - & 0.0080 \\
\hline & $\mathrm{AA}$ & 0.0126 & 1.8491 & 166.3 & 2.8043 & - & - & - & 0.0087 \\
\hline & cis-NMF & 0.0113 & 1.8735 & 160.4 & 2.8084 & - & - & - & 0.0087 \\
\hline & cis-NMA & 0.0134 & 1.8326 & 168.0 & 2.7929 & - & - & - & 0.0088 \\
\hline & trans-NMF & 0.0113 & 1.8715 & 161.5 & 2.8103 & - & - & - & 0.0087 \\
\hline & trans-NMA & 0.0135 & 1.8348 & 167.7 & 2.7945 & - & - & - & 0.0091 \\
\hline & DMF & 0.0119 & 1.8614 & 162.2 & 2.8035 & - & - & - & 0.0091 \\
\hline & DMA & 0.0136 & 1.8252 & 169.5 & 2.7891 & - & - & - & 0.0091 \\
\hline \multirow{8}{*}{ MeOH-amide (B) } & FA & 0.0137 & 1.8615 & 153.6 & 2.7992 & 0.0088 & 2.0569 & 139.5 & 0.0116 \\
\hline & AA & 0.0159 & 1.8615 & 153.6 & 2.7708 & 0.0089 & 2.0569 & 139.5 & 0.0126 \\
\hline & cis-NMF & 0.0153 & 1.8789 & 152.1 & 2.7792 & 0.0085 & 2.0439 & 141.1 & 0.0125 \\
\hline & cis-NMA & 0.0171 & 1.8446 & 154.6 & 2.7600 & 0.0084 & 2.0448 & 143.8 & 0.0131 \\
\hline & trans-NMF & 0.0110 & 1.8621 & 174.7 & 2.8312 & - & - & - & 0.0079 \\
\hline & trans-NMA & 0.0121 & 1.8393 & 176.6 & 2.8111 & - & - & - & 0.0076 \\
\hline & DMF & 0.0108 & 1.8473 & 170.4 & 2.8099 & - & - & - & 0.0070 \\
\hline & DMA & 0.0122 & 1.8357 & 171.7 & 2.8021 & - & - & - & 0.0095 \\
\hline \multirow{4}{*}{ Amide-MeOH } & FA & - & - & - & - & 0.0049 & 1.9530 & 169.5 & 0.0039 \\
\hline & AA & - & - & - & - & 0.0033 & 1.9908 & 164.1 & 0.0031 \\
\hline & trans-NMF & - & - & - & - & 0.0057 & 1.9584 & 169.9 & 0.0043 \\
\hline & trans-NMA & - & - & - & - & 0.0055 & 1.9921 & 164.4 & 0.0028 \\
\hline
\end{tabular}

${ }^{a} \Delta \mathrm{r}(\mathrm{OH})=\mathrm{r}_{\text {complex }}-\mathrm{r}_{\mathrm{MeOH}}$, is the change in the $\mathrm{OH}$ bond length upon complexation; ${ }^{\mathrm{b}}$ Inter-molecular hydrogen bond distance; ${ }^{\mathrm{c}}$ Inter-molecular hydrogen bond angle; $\mathrm{d}$ Contact distance between the two oxygen atoms in the hydrogen bond $(-\mathrm{O}-\mathrm{H} \cdots \mathrm{O}=)$; ${ }^{\mathrm{e}} \Delta \mathrm{r}(\mathrm{NH})=\mathrm{r}_{\text {complex }}-\mathrm{r}_{\text {amide, }}$ is the change in the NH bond length upon complexation; ${ }^{\mathrm{f}} \Delta \mathrm{r}(\mathrm{C}=\mathrm{O})=\mathrm{r}_{\text {complex }}-\mathrm{r}_{\text {amide, }}$ is the change in the $\mathrm{C}=\mathrm{O}$ bond length upon complexation; FA: formamide; NMF: $N$-methylformamide; DMF: $N, N$-dimethylformamide; AA: acetamide; NMA: $N$-methylacetamide; DMA: N,N-dimethylacetamide. 
The formation of a strong hydrogen bond between the $\mathrm{OH}$ group of $\mathrm{MeOH}$ and the carbonyl group leads to an elongation of the $\mathrm{C}=\mathrm{O}$ bond $(\Delta \mathrm{r}(\mathrm{C}=\mathrm{O})$ in Table 1$)$, which is about $0.007-0.013 \AA$ in the $\mathrm{MeOH}$-amide (A) and (B) complexes. In an early study on hydrogen bonded complexes between lactones with 3,4-dinitrophenol, the $\mathrm{C}=\mathrm{O}$ bonds were calculated to be elongated by $0.011-0.017 \AA$ (B3LYP $/ 6-311+\mathrm{G}^{*}$ ) [36]. In addition, the $\mathrm{C}=\mathrm{O}$ bonds also marginally increase by about $0.003-0.004 \AA$ in the amide- $\mathrm{MeOH}$ complexes. The hydrogen bond angles in the four cyclic structures, namely, $\mathrm{MeOH}-\mathrm{FA}(\mathrm{B}), \mathrm{MeOH}-\mathrm{AA}(\mathrm{B}), \mathrm{MeOH}-$ cis-NMF (B), $\mathrm{MeOH}-$ cis-NMA (B), deviate within $30^{\circ}$ from the ideal linear orientation. The hydrogen bond angles of the remaining structures vary from $158^{\circ}$ to $177^{\circ}$.

Furthermore, it is worth noting that the unsubstituted amides are less basic than the methyl substituted ones. The inductive effect of the methyl group enhances the basicity of the carbonyl group [36,37]. It can be seen that the changes in the $\mathrm{OH}$ bond of $\mathrm{MeOH}$ upon complexation are increased from FA to AA, NMF to NMA, DMF to DMA, FA to NMF, and AA to NMA (Table 1). DMF and DMA are substituted with two methyl groups, but the $\mathrm{OH}$ bond is marginally changed as compared with the mono-substituted NMF and NMA. When amide acts as a hydrogen bond donor, the changes of the NH bond upon complexation is decreased from FA to AA, trans-NMF to trans-NMA, but increased from FA to trans-NMF, AA to trans-NMA. Therefore, the substitution on the carbonyl group can enhance the strength of the hydrogen bond donor on amide, but the substitution on the amine group may weaken the strength of the hydrogen bond donor on amide.

\subsection{Interaction Energy}

The thermal properties were calculated at the B3LYP-D3/aug-cc-pVTZ level at $298.15 \mathrm{~K}$ and $1 \mathrm{~atm}$, and the binding energy $(B E)$, enthalpy of formation $\left(\Delta H_{298 K}^{\theta}\right)$ and Gibbs free energy of formation $\left(\Delta G_{298 K}^{\theta}\right)$ are summarized in Table 2. The values computed with the B3LYP-D3 functional have been found to give reasonable hydrogen bonding interaction energies [38-41]. The $B E s$ of the $\mathrm{MeOH}$ complexes are in the range of -21 to $-39 \mathrm{~kJ} \cdot \mathrm{mol}^{-1}$. In an early study, the $B E s$ of 3,4-dinitrophenol (DNP) with lactones ( $\alpha$-acetolactone, $\beta$-propiolactone, $\gamma$-butyrolactone, $\delta$-valerolactone, $\varepsilon$-caprolactone) were calculated to be -22.8 to $-47.4 \mathrm{~kJ} \cdot \mathrm{mol}^{-1}$ (B3LYP $/ 6-311++\mathrm{G}^{* *}$ ) [36]. The calculated BEs for the MeOH-dimethylamine and $\mathrm{MeOH}$-trimethylamine complexes were calculated to be $-25 \sim-27 \mathrm{~kJ} \cdot \mathrm{mol}^{-1}$ (B3LYP/aug-cc-pVTZ) [24]. In general, the $\mathrm{MeOH}$-amide (B) complexes are more stable than their corresponding $\mathrm{MeOH}$-amide (A) and amide-MeOH complexes. However, the $\mathrm{MeOH}$-amide (A) structures of trans-NMA, DMF and DMA are very closed to their corresponding $\mathrm{MeOH}$-amide (B) structures in terms of $B E s$, therefore, both should be present as an equilibrium mixture in the gas phase.

The MeOH-cis-NMF (B) and MeOH-cis-NMA (B) complexes are relatively more stable than their corresponding $\mathrm{MeOH}$-trans-amide (B) conformers, although the trans-NMF and trans-NMA are much more stable than their cis-monomers. For the MeOH-NMF and MeOH-NMA complexes, the energy of cis- and trans- conformers are very close to each other.

\subsection{OH-Stretching Vibrational Frequencies}

IR spectroscopy has been considered as one of the most important methods to investigate hydrogen bonding interactions. The red shift $(\Delta \widetilde{v})$ between the free and hydrogen bonded OH-stretching transition is very useful in determining the relative strength of hydrogen bonding interaction $[39,42]$. The calculated $\mathrm{C}=\mathrm{O}, \mathrm{NH}$ - and $\mathrm{OH}$-stretching fundamental transition wavenumbers and the red shifts upon complexation of the complexes at the B3LYP-D3/aug-cc-pVTZ level are summarized in Table 3. 
Table 2. Calculated binding energy ( $B E)$, zero-point vibrational energy (ZPVE), enthalpy of formation $\left(\Delta H_{298 K}^{\theta}\right)$, Gibbs free energy of formation $\left(\Delta G_{298 K}^{\theta}\right)$ at $298.15 \mathrm{~K}$ and $1 \mathrm{~atm}$ for the $\mathrm{MeOH}$-amide and amide-MeOH complexes ${ }^{\text {a }}$.

\begin{tabular}{cccccc}
\hline Type & Conformer & $\mathbf{B E}^{\mathbf{b}}$ & $\mathbf{Z P V E}$ & $\mathbf{\Delta H}_{\mathbf{2 9 8 K}}^{\boldsymbol{\theta}}$ & $\boldsymbol{\Delta \mathbf { G } _ { \mathbf { 2 9 8 K } } ^ { \boldsymbol { \theta } }}$ \\
\hline & $\mathrm{FA}$ & -23.8 & 6.0 & -23.0 & 8.9 \\
& AA & -29.0 & 6.4 & -28.7 & 9.1 \\
& cis-NMF & -25.8 & 5.8 & -24.7 & 7.3 \\
MeOH-amide (A) & cis-NMA & -30.5 & 5.9 & -29.6 & 4.6 \\
& trans-NMF & -25.7 & 5.4 & -24.4 & 7.6 \\
& trans-NMA & -30.3 & 6.1 & -29.7 & 10.0 \\
& DMF & -26.7 & 5.5 & -25.4 & 6.3 \\
& DMA & -30.8 & 5.8 & -29.8 & 4.4 \\
\hline & FA & -35.6 & 8.1 & -36.3 & 2.6 \\
& AA & -37.6 & 7.9 & -38.2 & 9.1 \\
& cis-NMF & -37.9 & 7.4 & -38.2 & 0.9 \\
cis-NMA & -39.2 & 7.3 & -39.4 & 2.1 \\
& trans-NMF & -29.0 & 6.2 & -28.4 & 9.6 \\
& trans-NMA & -30.1 & 6.8 & -29.9 & 12.0 \\
& DMF & -27.9 & 5.7 & -26.6 & 5.3 \\
& DMA & -29.0 & 6.2 & -28.3 & 8.5 \\
\hline & FA & -21.2 & 4.8 & -19.5 & 8.3 \\
& AA & -21.5 & 5.3 & -20.2 & 13.1 \\
amide-MeOH & trans-NMF & -22.0 & 3.7 & -19.7 & 9.8 \\
& trans-NMA & -21.9 & 4.8 & -20.3 & 17.0 \\
\hline
\end{tabular}

a Obtained at the B3LYP-D3/aug-cc-pVTZ level; energies are in $\mathrm{kJ} \cdot \mathrm{mol}^{-1} ;{ }^{\mathrm{b}} B E s$ are corrected with ZPVE; FA: formamide; NMF: $N$-methylformamide; DMF: $N, N$-dimethylformamide; AA: acetamide; NMA: $\mathrm{N}$-methylacetamide; DMA: $\mathrm{N}, \mathrm{N}$-dimethylacetamide.

Table 3. Calculated bonded $\mathrm{OH}-, \mathrm{NH}-$ and $\mathrm{C}=\mathrm{O}$ stretching vibrational wavenumbers and red shifts (in $\mathrm{cm}^{-1}$ ) of the $\mathrm{MeOH}$-amide and amide-MeOH complexes at the B3LYP-D3/aug-cc-pVTZ level.

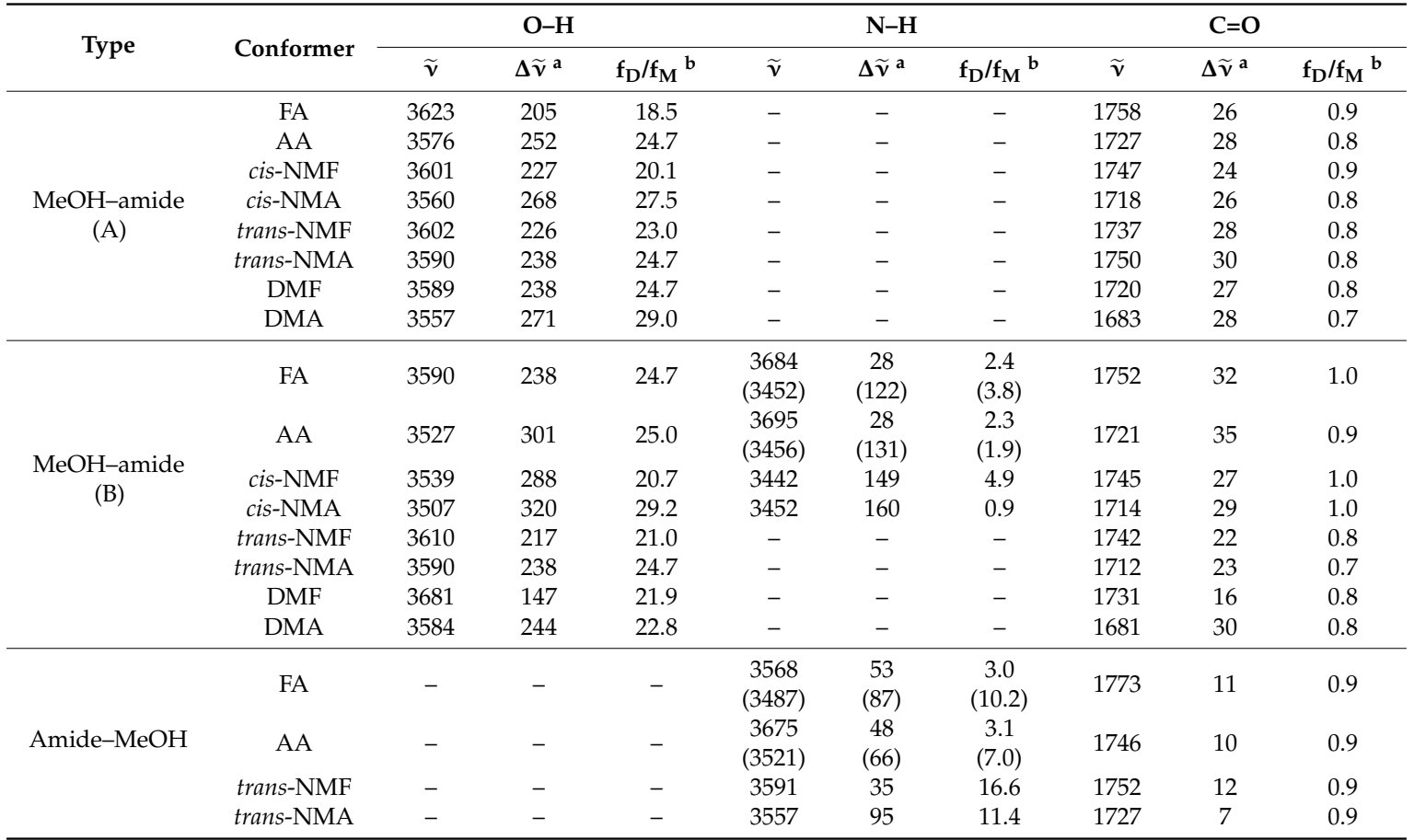

The values in the parentheses are the parameters for the symmetric NH-stretching transitions; ${ }^{a} \Delta \widetilde{v}=\widetilde{v}_{\text {monomer }}-\widetilde{v}_{\text {complex }} ;{ }^{b} f_{D} / f_{M}$ represents the increase of intensity upon complexation; FA: formamide; NMF: $N$-methylformamide; DMF: $N, N$-dimethylformamide; AA: acetamide; NMA: $N$-methylacetamide; DMA: $\mathrm{N}, \mathrm{N}$-dimethylacetamide. 
The red shifts of the $\mathrm{OH}$-stretching frequencies in the $\mathrm{MeOH}$-amide (A) and (B) complexes were in the range of $147-320 \mathrm{~cm}^{-1}$ and the intensities were increased more than 19 times with respect to the $\mathrm{MeOH}$ monomer. The red shifts of the $\mathrm{OH}$-stretching vibrational transition of the $\mathrm{O}-\mathrm{H} \cdots \mathrm{O}$ hydrogen bond upon complexation were reported to be $169 \mathrm{~cm}^{-1}$ (B3LYP-D3/aug-cc-pVTZ) for $\mathrm{MeOH}-\mathrm{N}$-nitrosodimethylamine (NDMA) [43]. For MeOH-dimethyl ether (DME), the calculated $\mathrm{O}-\mathrm{H} \cdots \mathrm{O}$ hydrogen bond frequency was $3659 \mathrm{~cm}^{-1}$ (B3LYP/aug-cc-pVTZ) with a red shift of $170 \mathrm{~cm}^{-1}$ and the corresponding intensity was increased by 18 times as compared with the monomer [44].

Both the AA and FA complexes have a $\mathrm{NH}_{2}$ group and the calculated IR spectra show larger red shifts of the symmetric NH-stretching transitions $\left(66-131 \mathrm{~cm}^{-1}\right)$ than those of their corresponding anti-symmetric $\mathrm{NH}$-stretching transitions $\left(28-53 \mathrm{~cm}^{-1}\right)$. The enhancement of the intensities is less than 10 times with respect to the monomers. A similar trend was found in previous study on the hydrogen bonding interactions between $\mathrm{H}_{2} \mathrm{O} / \mathrm{MeOH}$ with melamine (MA) [44]. $\mathrm{MA}$ has three $\mathrm{NH}_{2}$ groups, and the most stable structure was formed via $\mathrm{O}-\mathrm{H} \cdots \mathrm{O}$ and $\mathrm{N}-\mathrm{H} \cdots \mathrm{O}$ hydrogen bonds. The red shifts of the symmetric NH-stretching transitions were calculated to be $71-86 \mathrm{~cm}^{-1}$ (B3LYP/aug-cc-pVTZ) and values of the anti-symmetric NH-stretching transitions were $28-32 \mathrm{~cm}^{-1}$ (B3LYP/aug-cc-pVTZ). In contrast, the NH-stretching transitions in the $\mathrm{MeOH}-$ cis-NMF (B) and MeOH-cis-NMA (B) complexes are much more red shifted $\left(149-60 \mathrm{~cm}^{-1}\right)$ than those in the MeOH-trans-NMF and MeOH-trans-NMA complexes $\left(35-95 \mathrm{~cm}^{-1}\right)$. MeOH acts as a hydrogen bond donor and acceptor simultaneously in the former two complexes, which greatly enhances the electronegativity of the oxygen atom of $\mathrm{MeOH}$. In addition, $\mathrm{MeOH}$ acts a hydrogen acceptor at the same time for both the $\mathrm{N}-\mathrm{H} \cdots \mathrm{O}$ and $\mathrm{C}-\mathrm{H} \cdots \mathrm{O}$ hydrogen bonds in the trans-NMF-MeOH and trans-NMA-MeOH complexes. Under such circumstances, the contribution of $\mathrm{MeOH}$ to each acceptor will be significantly reduced. As a result, the red shifts of the NH-stretching transitions are much smaller than those in the MeOH-cis-NMF (B) and $\mathrm{MeOH}$-cis-NMA (B) complexes.

The calculated $\mathrm{C}=\mathrm{O}$ stretching fundamental transition wavenumbers and the red shifts of the complexes are listed in Table 3. The $\mathrm{C}=\mathrm{O}$ stretching vibrational transition of the $\mathrm{O}-\mathrm{H} \cdots \mathrm{O}=\mathrm{C}$ bonded $\mathrm{MeOH}$-amide complexes were calculated to be red shifted by $16-35 \mathrm{~cm}^{-1}$ with respect to the corresponding amide monomers. The red shifts were caused by electronic charge released from the $\mathrm{C}=\mathrm{O}$ bond of amide to the $\mathrm{OH}$ of alcohol during the hydrogen bond formation [45]. In a previous study, comparable red shifts of the $C=O$ stretching transition $\left(21-34 \mathrm{~cm}^{-1}\right)$ were observed between phenol derivatives and methyl acetate/methyl chloroacetate in carbon tetrachloride solution by FTIR spectroscopy [46]. Moreover, the $\mathrm{C}=\mathrm{O}$ stretching bands were red shifted less than $40 \mathrm{~cm}^{-1}$ (B3LYP/6-311+G $\mathrm{G}^{* *}$ ) in the $\mathrm{MeOH}$ complexes with various cyclic ketones, lactones, lactams, and $\mathrm{N}$-methyl lactams [37]. The $\mathrm{C}=\mathrm{O}$ stretching vibrational transition of the $\mathrm{O}-\mathrm{H} \cdots \mathrm{O}=\mathrm{C}$ bonded amide-MeOH complexes were calculated to be red shifted by $7-12 \mathrm{~cm}^{-1}$ with respect to the corresponding amide monomers.

\subsection{Topological and GKS-EDA Analysis}

Topological analyses by Markovian electron localization function (ELF) [47], delocalization behavior [48], and electron density $\rho(\mathrm{r})$ using quantum theory of atoms in molecules (QTAIM) [25,26], are commonly used to analyze structure, bonding and chemical reactivity. In this study, AIM analysis was used to evaluate the hydrogen bond strength. AIM analysis was performed using the wave functions calculated at the B3LYP-D3/aug-cc-pVTZ level. The AIM plots of the complexes with bond critical points (BCPs), ring critical points (RCPs) and electron density paths are shown in Figures 4 and 5. The AIM molecular graph shows the BCPs along the lines joining the $\mathrm{OH}$ (or $\mathrm{NH}$ ) and $\mathrm{O}$ atom for the $\mathrm{MeOH}$-amide and amide-MeOH complexes, which clearly prove the presence of hydrogen bonds. The topological parameters, including electron density $\rho(\mathrm{r})$, Laplacian $\nabla^{2} \rho(\mathrm{r})$ at the BCPs, and change in atomic charge $\Delta q(\mathrm{H})$ at the $\mathrm{H}$ atom with the B3LYP-D3/aug-cc-pVTZ method are listed in Table 4. 


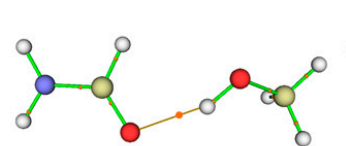<smiles>[2H]OB(O)OOOOOC(=O)O</smiles>
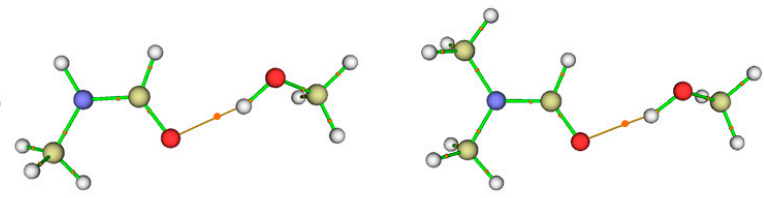

$\mathrm{MeOH}-\mathrm{FA}(\mathrm{A})$

$\mathrm{MeOH}-c i$-NMF (A)

MeOH-trans -NMF (A)

MeOH-DMF (A)
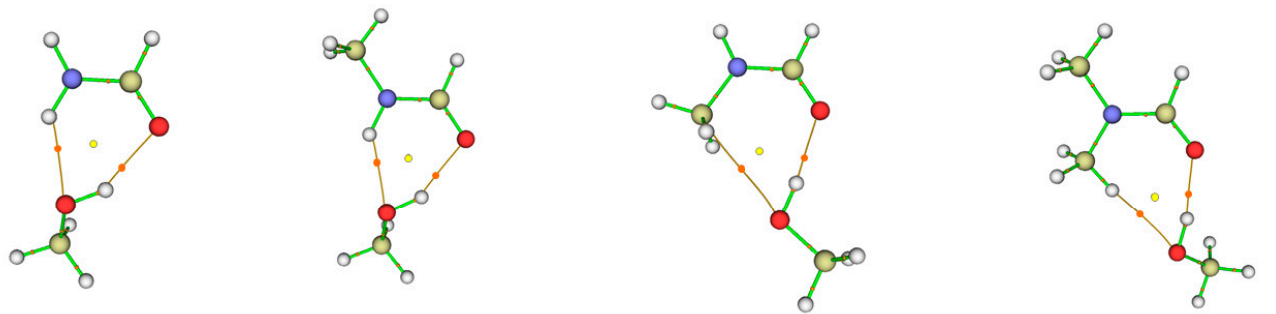

$\mathrm{MeOH}-\mathrm{FA}(\mathrm{B})$

$\mathrm{MeOH}-c i$-NMF (B)

MeOH-trans-NMF (B)

MeOH-DMF (B)<smiles>O=C(O)OOOOOB(O)OO</smiles>

FA- $\mathrm{MeOH}$

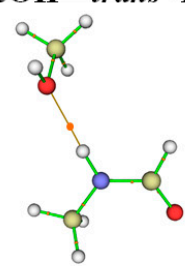

trans -NMF-MeOH

Figure 4. The Atoms in Molecules (AIM) plots of the MeOH-formamide and formamide-MeOH complexes obtained at the B3LYP-D3/aug-cc-pVTZ level; The bond critical points (BCPs) and ring critical points (RCPs) are presented by the ginger and yellow balls, respectively; FA: formamide; NMF: $N$-methylformamide; DMF: $N, N$-dimethylformamide; MeOH: methanol.
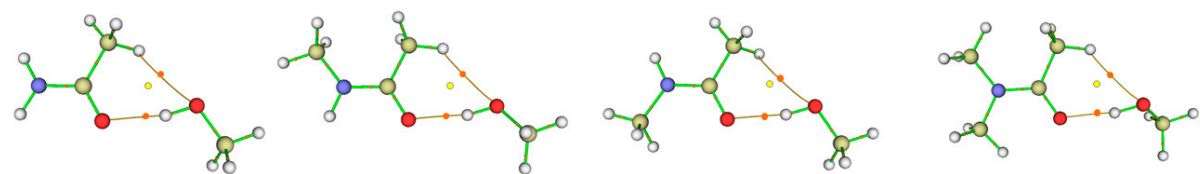

$\mathrm{MeOH}-\mathrm{AA}(\mathrm{A})$

MeOH-cis-NMA (A)

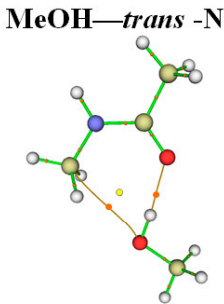

МеOH-DMA (A)
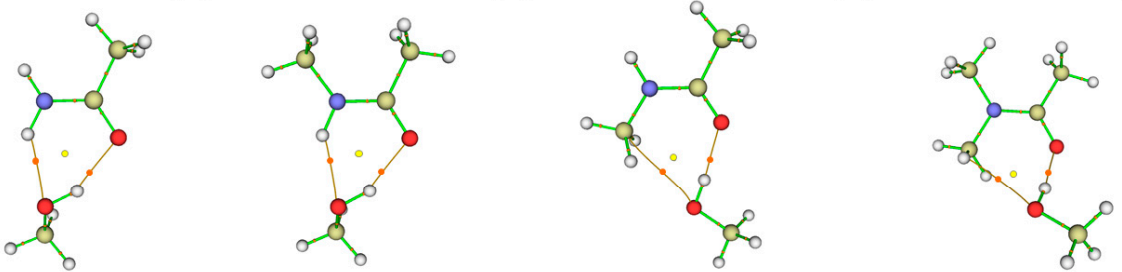

$\mathrm{MeOH}-\mathrm{AA}(\mathrm{B})$

MeOH-cis-NMA (B)

MeOH-trans -NMA (B)

MeOH-DMA(B)
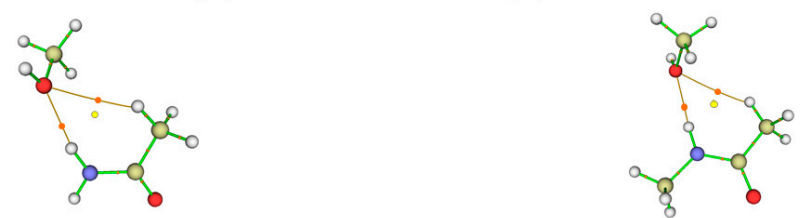

АA-MeOH

trans -NMA-MeOH

Figure 5. The Atoms in Molecules (AIM) plots of the MeOH-acetamide and acetamide-MeOH complexes obtained at the B3LYP-D3/aug-cc-pVTZ level. The bond critical points (BCPs) and ring critical points (RCPs) are presented by the ginger and yellow balls, respectively; AA: acetamide; NMA: $\mathrm{N}$-methylacetamide; DMA: $\mathrm{N}, \mathrm{N}$-dimethylacetamide; $\mathrm{MeOH}$ : methanol. 
Table 4. Atoms in Molecules (AIM) parameters for the $\mathrm{MeOH}$-amide and amide-MeOH complexes obtained at the B3LYP-D3/aug-cc-pVTZ level (distances in $\AA$; all other values in a.u.).

\begin{tabular}{|c|c|c|c|c|c|c|c|c|c|}
\hline \multirow{2}{*}{ Type } & \multirow{2}{*}{ Conformer } & \multicolumn{4}{|c|}{$\mathrm{O}-\mathrm{H} \cdots \mathrm{O}(\mathrm{C}-\mathrm{H} \cdots \mathrm{O})$} & \multicolumn{4}{|c|}{$\mathrm{N}-\mathrm{H} \cdots \mathrm{O}(\mathrm{C}-\mathrm{H} \cdots \mathrm{O})$} \\
\hline & & $\Delta q(\mathrm{H})^{\mathrm{a}}$ & $\rho(\mathrm{BCP})^{\mathrm{b}}$ & $\nabla^{2} \rho(\mathrm{BCP})^{\mathrm{c}}$ & $r^{d}$ & $\Delta q(\mathrm{H})^{\mathrm{a}}$ & $\rho(\mathrm{BCP})^{\mathrm{b}}$ & $\nabla^{2} \rho(\mathrm{BCP})^{\mathrm{c}}$ & $r^{d}$ \\
\hline \multirow{5}{*}{$\begin{array}{l}\mathrm{MeOH} \text {-amide } \\
\text { (A) }\end{array}$} & FA & 0.036 & 0.0230 & 0.1255 & - & - & - & - & - \\
\hline & cis-NMF & 0.040 & 0.0238 & 0.1318 & - & - & - & - & - \\
\hline & cis-NMA & 0.049 & 0.0248 & 0.1478 & 1.8697 & $(0.045)$ & $(0.0081)$ & $(0.0359)$ & $(1.0279)$ \\
\hline & trans-NMF & 0.039 & 0.0239 & 0.1322 & - & - & - & - & - \\
\hline & DMA & 0.050 & 0.0252 & 0.1513 & 1.8371 & $(0.031)$ & $(0.0083)$ & $(0.0356)$ & $(0.9545)$ \\
\hline \multirow{4}{*}{$\begin{array}{l}\mathrm{MeOH} \text {-amide } \\
\text { (B) }\end{array}$} & FA & 0.044 & 0.0226 & 0.1254 & 1.6165 & 0.060 & 0.0178 & 0.0939 & 1.5660 \\
\hline & AA & 0.050 & 0.0244 & 0.1411 & 1.6115 & 0.059 & 0.0178 & 0.0922 & 1.5223 \\
\hline & cis-NMF & 0.048 & 0.0238 & 0.1346 & 1.6220 & 0.060 & 0.0184 & 0.0932 & 1.5306 \\
\hline & cis-NMA & 0.056 & 0.0251 & 0.1476 & 1.5958 & 0.053 & 0.0183 & 0.0939 & 1.4802 \\
\hline \multirow{4}{*}{ Amide-MeOH } & FA & - & - & - & - & 0.061 & 0.0204 & 0.1052 & - \\
\hline & AA & $(0.016)$ & $(0.0063)$ & $(0.0225)$ & $(0.8941)$ & 0.055 & 0.0199 & 0.1013 & 1.8910 \\
\hline & trans-NMF & - & - & - & - & 0.066 & 0.0204 & 0.1036 & - \\
\hline & trans-NMA & $(0.016)$ & $(0.0059)$ & $(0.0210)$ & $(0.7357)$ & 0.052 & 0.0198 & 0.1032 & 1.9016 \\
\hline
\end{tabular}

The values in the parentheses are the AIM parameters for the $\mathrm{C}-\mathrm{H} \cdots \mathrm{O}$ hydrogen bonds; ${ }^{a}$ The change in atomic charge at the $\mathrm{H}$ atom; ${ }^{\mathrm{b}}$ The electron density at the BCPs; ${ }^{\mathrm{c}}$ The Laplacian electron density at the BCPs; ${ }^{\mathrm{d}}$ The distance between a BCP and an RCP; FA: formamide; NMF: $N$-methylformamide; DMF: $\mathrm{N}, \mathrm{N}$-dimethylformamide; AA: acetamide; NMA: $\mathrm{N}$-methylacetamide; DMA: $\mathrm{N}, \mathrm{N}$-dimethylacetamide.

The $\mathrm{C}-\mathrm{H} \cdots \mathrm{O}$ hydrogen bonds have been widely studied in recent literature, where the hydrogen bond donors were electronegative oxygen atoms of various functional groups $[49,50]$. From an energetic point of view, $\mathrm{C}-\mathrm{H} \cdots \mathrm{O}$ hydrogen bonds are much weaker than the classical $\mathrm{X}-\mathrm{H} \cdots \mathrm{Y}$ hydrogen bonds where the $\mathrm{X}$ and $\mathrm{Y}$ are electronegative atoms such as nitrogen, oxygen or sulfur. A typical feature for $\mathrm{C}-\mathrm{H} \cdots \mathrm{O}$ hydrogen bonds are the blue shifts of the $\mathrm{C}-\mathrm{H}$ vibrational fundamental transitions with lower transition intensities with respect to the monomer [51,52]. The $\mathrm{C}-\mathrm{H} \cdots \mathrm{O}$ hydrogen bonds are weak non-covalent interactions and they are referred to as cooperative hydrogen bonding interactions. The cooperative interactions play an important role in determining the structure and properties of materials [53,54].

According to the criteria proposed by Popelier, the electron density $\rho(\mathrm{BCP})$ at the $\mathrm{BCPs}$ is in the range of $0.002-0.040$ a.u. for a hydrogen bond [55,56]. The electron densities at the BCPs are in the ranges of $0.0226-0.0252,0.0059-0.0095$ and $0.0178-0.0204$ a.u. for the $\mathrm{O}-\mathrm{H} \cdots \mathrm{O}, \mathrm{C}-\mathrm{H} \cdots \mathrm{O}$ and $\mathrm{N}-\mathrm{H} \cdots \mathrm{O}$ hydrogen bonds, respectively. Similarly, the Laplacian of charge density $\nabla^{2} \rho(\mathrm{BCP})$ of the complexes is in the ranges of $0.1254-0.1513,0.0210-0.0412$ and $0.0922-0.1052$ a.u. for the $\mathrm{O}-\mathrm{H} \cdots \mathrm{O}, \mathrm{C}-\mathrm{H} \cdots \mathrm{O}$ and $\mathrm{N}-\mathrm{H} \cdots \mathrm{O}$ hydrogen bonds, respectively. These values for the $\mathrm{C}-\mathrm{H} \cdots \mathrm{O}$ and $\mathrm{N}-\mathrm{H} \cdots \mathrm{O}$ hydrogen bonds are in the range of the Laplacian criteria $(0.014-0.139$ a.u.) for a hydrogen bond $[55,56]$. The values for the $\mathrm{O}-\mathrm{H} \cdots \mathrm{O}$ hydrogen bond are slightly larger than the upper value of the Laplacian criteria.

The distance between a BCP and an RCP has been used as a criteria to measure the structural stability of a hydrogen bond [57]. The MeOH-amide (A), MeOH-trans-NMA (B) and MeOH-DMA (B) complexes are formed by two hydrogen bonds: $\mathrm{O}-\mathrm{H} \cdots \mathrm{O}$ and $\mathrm{C}-\mathrm{H} \cdots \mathrm{O}$. The distances between the $\mathrm{BCP}$ of the $\mathrm{O}-\mathrm{H} \cdots \mathrm{O}$ hydrogen bond and the $\mathrm{RCP}$ in the multi-membered rings are much larger (1.8371-2.0597 $\AA$ ) than their corresponding distances between the BCP of the $\mathrm{C}-\mathrm{H} \cdots \mathrm{O}$ hydrogen bond and the RCP $(0.7400-1.1806 \AA)$. This shows that the $\mathrm{O}-\mathrm{H} \cdots \mathrm{O}$ hydrogen bonds are relatively more stable than the $\mathrm{C}-\mathrm{H} \cdots \mathrm{O}$ hydrogen bond in the $\mathrm{MeOH}$-amide (A), MeOH-trans-NMA (B) and MeOH-DMA (B) complexes. The MeOH-FA/AA/cis-NMF/cis-NMA (B) complexes are formed by two hydrogen bonds: $\mathrm{O}-\mathrm{H} \cdots \mathrm{O}$ and $\mathrm{N}-\mathrm{H} \cdots \mathrm{O}$. The distances between the $\mathrm{BCP}$ of the $\mathrm{O}-\mathrm{H} \cdots \mathrm{O}$ hydrogen bond and the $\mathrm{RCP}$ are slightly larger than those of $\mathrm{N}-\mathrm{H} \cdots \mathrm{O}$. In the AA-MeOH and trans-NMA-MeOH complexes, 
the distances between the $\mathrm{BCP}$ and the $\mathrm{RCP}$ clearly indicate that the $\mathrm{N}-\mathrm{H} \cdots \mathrm{O}$ hydrogen bonds are much stronger than the $\mathrm{C}-\mathrm{H} \cdots \mathrm{O}$ hydrogen bond.

To get a better insight into the nature of hydrogen bonding interaction, it is important to decompose the non-covalent interaction into various "components" and to quantify their contributions to the binding energy. We have utilized Su's generalized Kohn-Sham energy decomposition analysis (GKS-EDA) for energy decomposition analysis [58]. GKS-EDA method allows to fragment the total interaction energy $\left(\mathrm{E}^{\mathrm{INT}}\right)$ into electrostatic energy $\left(\mathrm{E}^{\mathrm{ES}}\right)$, exchange energy $\left(\mathrm{E}^{\mathrm{EX}}\right)$, repulsion energy $\left(\mathrm{E}^{\mathrm{REP}}\right)$, polarization energy $\left(\mathrm{E}^{\mathrm{POL}}\right)$, Grimme's dispersion energy $\left(\mathrm{E}^{\mathrm{DISP}}\right)$ and correlation energy $\left(E^{\mathrm{CORR}}\right)$. The total interaction energy along with the individual components were obtained using the GKS-EDA scheme at the B3LYP-D3/aug-cc-pVTZ level (Table 5). The attractive $\mathrm{E}^{\mathrm{DISP}}$ term computed in the GKS-EDA method arises due to the presence of electron correlation in the system [59]. The greater $\mathrm{E}^{\mathrm{ES}}$ values indicate the better orbital overlapping between hydrogen bond donor and acceptor. Furthermore, the large $\mathrm{E}^{\mathrm{EX}}$ and $\mathrm{E}^{\mathrm{REP}}$ terms also imply the feasibility of orbital overlapping between the two monomers. The $\mathrm{E}^{\mathrm{EX}}$ obtained from GKS-EDA analysis is similar to the charge transfer [60]. The $\mathrm{E}^{\mathrm{POL}}$ terms are also attractive in nature and such effects are considered by the orbital interactions between monomers which further allows charge shift between the respective monomers [61]. Figure 6 shows a graphical representation of the six components' contribution $(\%)$ in GKS-EDA at the B3LYP-D3/aug-cc-pVTZ level. The $E^{\text {REP }}$ term is positive, which is about $\sim 76 \%-82 \%$ of the total attractive energies. The negative values are the attractive components, i.e., $\mathrm{E}^{\mathrm{ES}}, \mathrm{E}^{\mathrm{EX}}, \mathrm{E}^{\mathrm{POL}}, \mathrm{E}^{\mathrm{DISP}}$, and $\mathrm{E}^{\mathrm{CORR}}$, and make a large contribution in stabilizing the bimolecular complexes. Among them, the terms $\mathrm{E}^{\mathrm{ES}}$ and $\mathrm{E}^{\mathrm{EX}}$ are the dominating contributors, about $30 \%-34 \%$ and $\sim 44 \%-46 \%$ to the total attractive energies, respectively. $\mathrm{E}^{\mathrm{ES}}$ and $\mathrm{E}^{\mathrm{EX}}$ are the main driving forces for the formation of the $\mathrm{MeOH}$ complexes. The $\mathrm{E}^{\mathrm{POL}}$ contribution is about $\sim 11 \%-14 \%$ to the total attractive energies. The $\mathrm{E}^{\mathrm{CORR}}\left(\sim 4 \%-5 \%\right.$ to the total attractive energies) and $\mathrm{E}^{\mathrm{DISP}}(\sim 4 \%-9 \%$ to the total attractive energies) contributions are close to each other and they are the smallest ones among the five attractive components. The decomposition of the total interaction energy shows that the contribution of $\mathrm{E}^{\mathrm{ES}}$ and $\mathrm{E}^{\mathrm{EX}}$ to total interaction energies is very large.

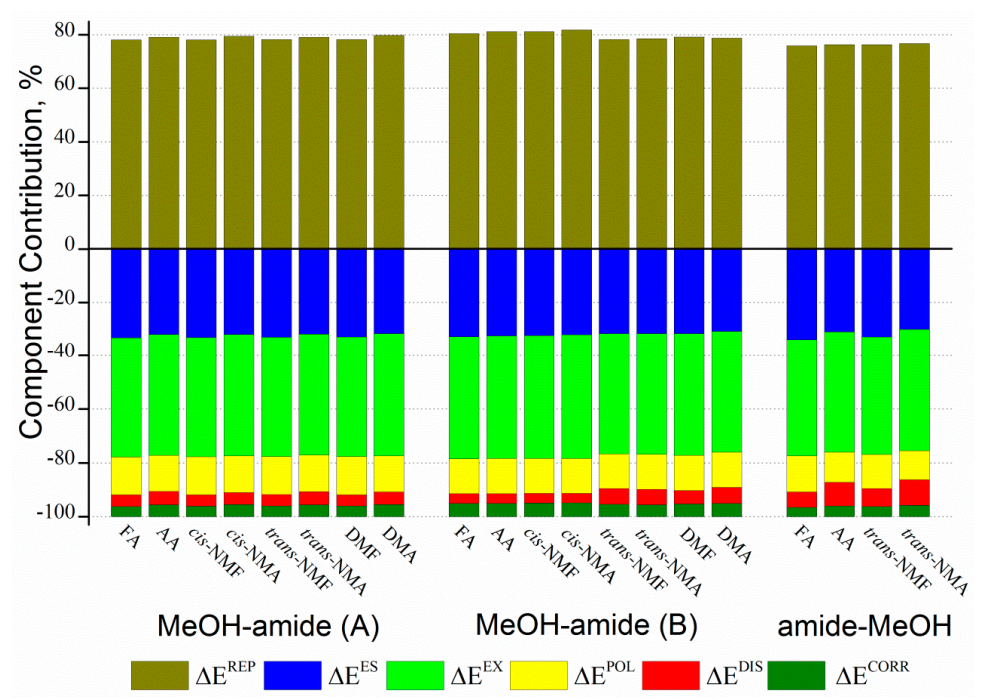

Figure 6. The six components' contribution (\%) to the total interaction energy in generalized Kohn-Sham energy decomposition analysis (GKS-EDA) at the B3LYP-D3/aug-cc-pVTZ level; Positive values are the repulsive component (repulsion energy $\left(\mathrm{E}^{\mathrm{REP}}\right)$ ), and the negative values are the attractive components (electrostatic energy $\left(\mathrm{E}^{\mathrm{ES}}\right)$, exchange energy $\left(\mathrm{E}^{\mathrm{EX}}\right)$, polarization energy $\left(E^{\mathrm{POL}}\right)$, correlation energy $\left(\mathrm{E}^{\mathrm{CORR}}\right)$ and Grimme's dispersion energy $\left(\mathrm{E}^{\mathrm{DISP}}\right)$ ); FA: formamide; NMF: $\mathrm{N}$-methylformamide; DMF: $\mathrm{N}, \mathrm{N}$-dimethylformamide; AA: acetamide; NMA: $\mathrm{N}$-methylacetamide; DMA: $N, N$-dimethylacetamide. 
Table 5. Results of generalized Kohn-Sham energy decomposition analysis (GKS-EDA) for the $\mathrm{MeOH}$-amide and amide-MeOH complexes at the B3LYP-D3/aug-cc-pVTZ level (all values in $\left.\mathrm{kJ} \cdot \mathrm{mol}^{-1}\right)^{\mathrm{a}}$.

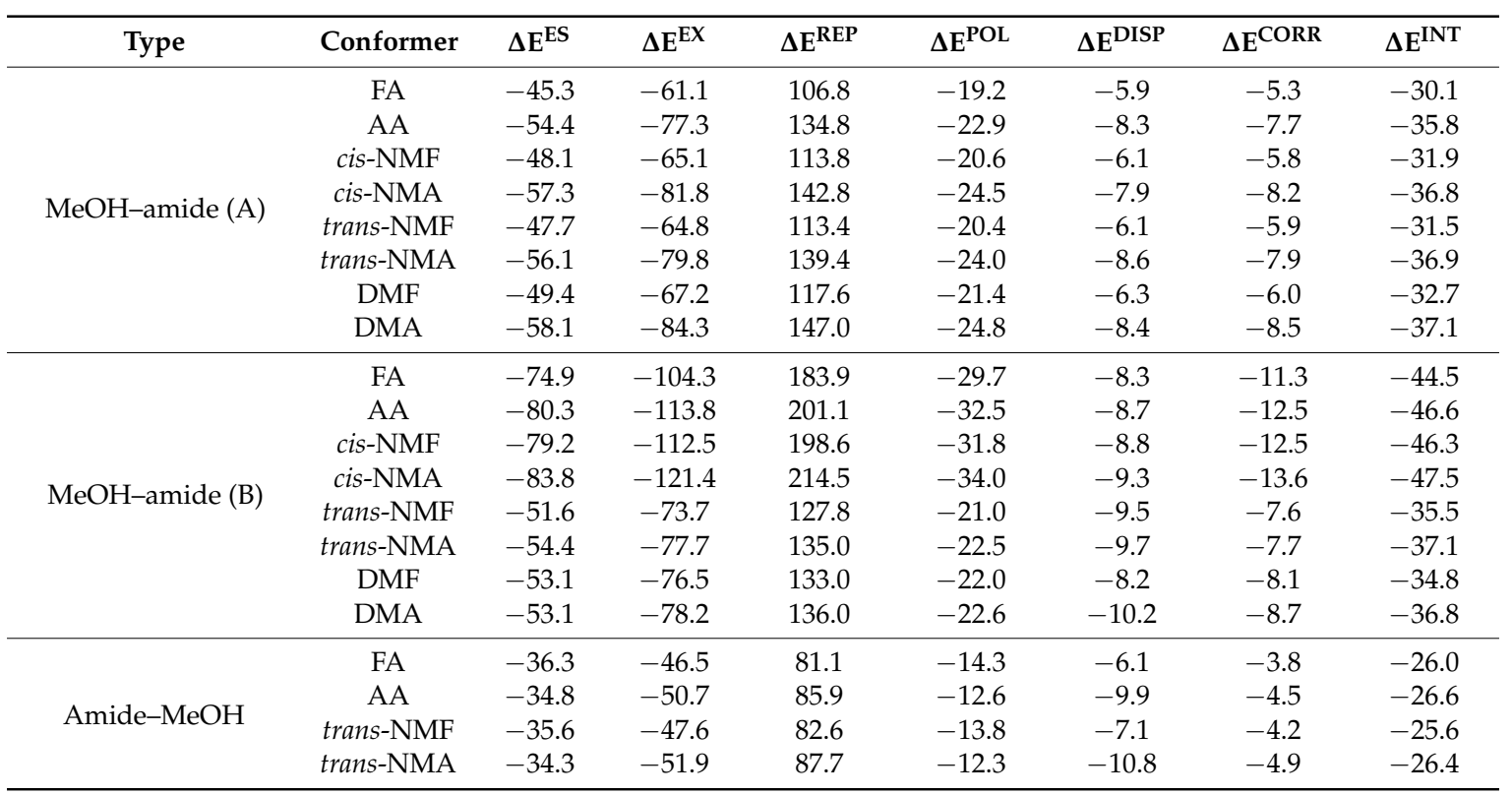

a The total interaction energy $\left(\Delta \mathrm{E}^{\mathrm{INT}}\right)$ is divided into electrostatic energy $\left(\Delta \mathrm{E}^{\mathrm{ES}}\right)$, exchange energy $\left(\Delta \mathrm{E}^{\mathrm{EX}}\right)$, repulsion energy $\left(\Delta \mathrm{E}^{\mathrm{REP}}\right)$, polarization energy $\left(\Delta \mathrm{E}^{\mathrm{POL}}\right)$, Grimme's dispersion energy $\left(\Delta \mathrm{E}^{\mathrm{DISP}}\right)$ and correlation energy $\left(\triangle \mathrm{E}^{\mathrm{CORR}}\right)$; FA: formamide; NMF: $N$-methylformamide; DMF: $N, N$-dimethylformamide; AA: acetamide; NMA: $N$-methylacetamide; DMA: $N, N$-dimethylacetamide.

\section{Computational Methods}

All calculations were performed using the Gaussian 09 (Revision E.01) set of programs [62]. Geometry optimizations were carried out using the B3LYP-D3 method with the aug-cc-pVTZ basis set. The B3LYP-D3 functional has been parameterized for describing dispersion interaction, which has been shown to make an important contribution [63]. The harmonic frequencies were calculated at the same level to characterize the stationary points found as minima of the potential energy surface and to evaluate the corresponding zero point vibrational energy (ZPVE). A "very tight" optimization convergence criteria and an "ultrafine" numerical integration grid was used for the DFT calculations to obtain reliable results $[64,65]$. The binding energies $(B E s)$ of the complexes were corrected with ZPVE. However, BEs are not corrected for the basis set superposition errors (BSSEs) [66]. The commonly used counterpoise $(\mathrm{CP})$ correction has been found to be important for small basis sets, but not for larger basis sets, such as aug-cc-pVTZ $[67,68]$.

The topological analysis of the electron density, $\rho(\mathrm{r})$, and its Laplacian function, $\nabla^{2} \rho(\mathrm{r})$ constitutes a powerful tool to investigate the nature of the chemical bonds $[25,26]$. According to Bader theory, the presence of a bond critical point $(\mathrm{BCP})$ is a universal indicator of the existence of a bonding interaction [69]. Topological analysis of the charge density was carried out by utilizing the AIM2000 program. The hydrogen bonding interactions were investigated using the generalized Kohn-Sham energy decomposition analysis (GKS-EDA), which is implemented in the GAMESS (US) program [70]. The total interaction energy $\left(\mathrm{E}^{\mathrm{INT}}\right)$ is divided into electrostatic energy $\left(\mathrm{E}^{\mathrm{ES}}\right)$, exchange energy $\left(\mathrm{E}^{\mathrm{EX}}\right)$, repulsion energy $\left(\mathrm{E}^{\mathrm{REP}}\right)$, polarization energy $\left(\mathrm{E}^{\mathrm{POL}}\right)$, Grimme's dispersion energy $\left(\mathrm{E}^{\mathrm{DISP}}\right)$ and correlation energy $\left(\mathrm{E}^{\mathrm{CORR}}\right)$ [27].

\section{Conclusions}

The hydrogen bonded complexes between methanol and amides show that, in the most stable conformation, amides behave simultaneously as a hydrogen bond donor and acceptor. The systematic 
changes of the substituent make the amides a better hydrogen bond acceptor but a worse hydrogen bond donor. Large red shifts $\left(147-320 \mathrm{~cm}^{-1}\right)$ of the $\mathrm{OH}$-stretching transition were found for the $\mathrm{MeOH}$ complexes. On the other hand, the red shifts of the NH-stretching transition were much smaller, below $160 \mathrm{~cm}^{-1}$. The $\mathrm{C}=\mathrm{O}$ stretching fundamental transitions were slightly red shifted upon complexation. AIM analyses show the existence of hydrogen bonds in the MeOH complexes, and GKS-EDA analysis demonstrates that the electrostatic, exchange, and repulsion energy play a major role in the total interaction energy.

Acknowledgments: This work was supported by Shandong Provincial Natural Science Foundation, China (ZR2014BQ013, ZR2016BB36), National Natural Science Foundation of China (21407095, 21577080) and High Performance Computing Center of Shandong University. The authors thank Peifeng Su from Xiamen University for providing the generalized Kohn-Sham energy decomposition analysis (GKS-EDA) software package.

Author Contributions: Hailiang Zhao and Lin Du conceived and designed the project; Hailiang Zhao and Shanshan Tang performed the calculations; Hailiang Zhao, Xiang Xu and Lin Du analyzed the data; Hailiang Zhao and Lin Du wrote the manuscript; All authors reviewed and improved the manuscript.

Conflicts of Interest: The authors declare no conflict of interest.

\section{References}

1. Mikhonin, A.V.; Bykov, S.V.; Myshakina, N.S.; Asher, S.A. Peptide secondary structure folding reaction coordinate: Correlation between UV raman amide III frequency, $\psi$ ramachandran angle, and hydrogen bonding. J. Phys. Chem. B 2006, 110, 1928-1943. [CrossRef] [PubMed]

2. Manas, E.S.; Getahun, Z.; Wright, W.W.; DeGrado, W.F; Vanderkooi, J.M. Infrared spectra of amide groups in $\alpha$-helical proteins: Evidence for hydrogen bonding between helices and water. J. Am. Chem. Soc. 2000, 122, 9883-9890. [CrossRef]

3. Walsh, S.T.R.; Cheng, R.P.; Wright, W.W.; Alonso, D.O.V.; Daggett, V.; Vanderkooi, J.M.; DeGrado, W.F. The hydration of amides in helices; a comprehensive picture from molecular dynamics, IR, and NMR. Protein Sci. 2003, 12, 520-531. [CrossRef] [PubMed]

4. Ge, X.; Wexler, A.S.; Clegg, S.L. Atmospheric amines-Part I. A review. Atmos. Environ. 2011, 45, 524-546. [CrossRef]

5. Zhu, L.; Schade, G.W.; Nielsen, C.J. Real-time monitoring of emissions from monoethanolamine-based industrial scale carbon capture facilities. Environ. Sci. Technol. 2013, 47, 14306-14314. [CrossRef] [PubMed]

6. Nielsen, C.J.; Herrmann, H.; Weller, C. Atmospheric chemistry and environmental impact of the use of amines in carbon capture and storage (ccs). Chem. Soc. Rev. 2012, 41, 6684-6704. [CrossRef] [PubMed]

7. Bunkan, A.J.C.; Mikoviny, T.; Nielsen, C.J.; Wisthaler, A.; Zhu, L. Experimental and theoretical study of the OH-initiated photo-oxidation of formamide. J. Phys. Chem. A 2016, 120, 1222-1230. [CrossRef] [PubMed]

8. Leach, J.; Blanch, A.; Bianchi, A.C. Volatile organic compounds in an urban airborne environment adjacent to a municipal incinerator, waste collection centre and sewage treatment plant. Atmos. Environ. 1999, 33, 4309-4325. [CrossRef]

9. Borduas, N.; da Silva, G.; Murphy, J.G.; Abbatt, J.P.D. Experimental and theoretical understanding of the gas phase oxidation of atmospheric amides with $\mathrm{OH}$ radicals: Kinetics, products, and mechanisms. J. Phys. Chem. A 2015, 119, 4298-4308. [CrossRef] [PubMed]

10. Kulmala, M. How particles nucleate and grow. Science 2003, 302, 1000-1001. [CrossRef] [PubMed]

11. Bianchi, F.; Trostl, J.; Junninen, H.; Frege, C.; Henne, S.; Hoyle, C.R.; Molteni, U.; Herrmann, E.; Adamov, A.; Bukowiecki, N.; et al. New particle formation in the free troposphere: A question of chemistry and timing. Science 2016, 352, 1109-1112. [CrossRef] [PubMed]

12. Zhang, R.; Khalizov, A.; Wang, L.; Hu, M.; Xu, W. Nucleation and growth of nanoparticles in the atmosphere. Chem. Rev. 2012, 112, 1957-2011. [CrossRef] [PubMed]

13. Zhang, R. Getting to the critical nucleus of aerosol formation. Science 2010, 328, 1366-1367. [CrossRef] [PubMed]

14. Temelso, B.; Morrell, T.E.; Shields, R.M.; Allodi, M.A.; Wood, E.K.; Kirschner, K.N.; Castonguay, T.C.; Archer, K.A.; Shields, G.C. Quantum mechanical study of sulfuric acid hydration: Atmospheric implications. J. Phys. Chem. A 2012, 116, 2209-2224. [CrossRef] [PubMed] 
15. Wang, L.; Khalizov, A.F.; Zheng, J.; Xu, W.; Ma, Y.; Lal, V.; Zhang, R. Atmospheric nanoparticles formed from heterogeneous reactions of organics. Nat. Geosci. 2010, 3, 238-242. [CrossRef]

16. Kulmala, M.; Kontkanen, J.; Junninen, H.; Lehtipalo, K.; Manninen, H.E.; Nieminen, T.; Petaja, T.; Sipila, M.; Schobesberger, S.; Rantala, P.; et al. Direct observations of atmospheric aerosol nucleation. Science 2013, 339, 943-946. [CrossRef] [PubMed]

17. Kulmala, M.; Petäjä, T.; Nieminen, T.; Sipilä, M.; Manninen, H.E.; Lehtipalo, K.; dal Maso, M.; Aalto, P.P.; Junninen, H.; Paasonen, P.; et al. Measurement of the nucleation of atmospheric aerosol particles. Nat. Protoc. 2012, 7, 1651-1667. [CrossRef] [PubMed]

18. Nadykto, A.B.; Yu, F.Q.; Jakovleva, M.V.; Herb, J.; Xu, Y.S. Amines in the earth's atmosphere: A density functional theory study of the thermochemistry of pre-nucleation clusters. Entropy 2011, 13, 554-569. [CrossRef]

19. Mellouki, A.; Wallington, T.J.; Chen, J. Atmospheric chemistry of oxygenated volatile organic compounds: Impacts on air quality and climate. Chem. Rev. 2015, 115, 3984-4014. [CrossRef] [PubMed]

20. Legreid, G.; Lööv, J.B.; Staehelin, J.; Hueglin, C.; Hill, M.; Buchmann, B.; Prevot, A.S.H.; Reimann, S. Oxygenated volatile organic compounds (ovocs) at an urban background site in zürich (europe): Seasonal variation and source allocation. Atmos. Environ. 2007, 41, 8409-8423. [CrossRef]

21. Rozenberg, M.; Loewenschuss, A.; Nielsen, C.J. Hydrogen bonding in the sulfuric acid-methanol-water system: A matrix isolation and computational study. J. Phys. Chem. A 2015, 119, 2271-2280. [CrossRef] [PubMed]

22. Almeida, J.; Schobesberger, S.; Kuerten, A.; Ortega, I.K.; Kupiainen-Maatta, O.; Praplan, A.P.; Adamov, A.; Amorim, A.; Bianchi, F.; Breitenlechner, M.; et al. Molecular understanding of sulphuric acid-amine particle nucleation in the atmosphere. Nature 2013, 502, 359-363. [CrossRef] [PubMed]

23. Kurtén, T.; Loukonen, V.; Vehkamaki, H.; Kulmala, M. Amines are likely to enhance neutral and ion-induced sulfuric acid-water nucleation in the atmosphere more effectively than ammonia. Atmos. Chem. Phys. 2008, 8, 4095-4103. [CrossRef]

24. Du, L.; Mackeprang, K.; Kjaergaard, H.G. Fundamental and overtone vibrational spectroscopy, enthalpy of hydrogen bond formation and equilibrium constant determination of the methanol-dimethylamine complex. Phys. Chem. Chem. Phys. 2013, 15, 10194-10206. [CrossRef] [PubMed]

25. Lane, J.R.; Contreras-Garcia, J.; Piquemal, J.-P.; Miller, B.J.; Kjaergaard, H.G. Are bond critical points really critical for hydrogen bonding? J. Chem. Theory Comput. 2013, 9, 3263-3266. [CrossRef] [PubMed]

26. Parthasarathi, R.; Subramanian, V.; Sathyamurthy, N. Hydrogen bonding without borders: An atoms-inmolecules perspective. J. Phys. Chem. A 2006, 110, 3349-3351. [CrossRef] [PubMed]

27. Su, P.F.; Jiang, Z.; Chen, Z.C.; Wu, W. Energy decomposition scheme based on the generalized kohn-sham scheme. J. Phys. Chem. A 2014, 118, 2531-2542. [CrossRef] [PubMed]

28. Shin, S.; Kurawaki, A.; Hamada, Y.; Shinya, K.; Ohno, K.; Tohara, A.; Sato, M. Conformational behavior of n-methylformamide in the gas, matrix, and solution states as revealed by IR and NMR spectroscopic measurements and by theoretical calculations. J. Mol. Struct. 2006, 791, 30-40. [CrossRef]

29. Kang, Y.K. Ab initio MO and density functional studies on trans and cis conformers of n-methylacetamide. J. Mol. Struct. 2001, 546, 183-193. [CrossRef]

30. Panuszko, A.; Gojlo, E.; Zielkiewicz, J.; Smiechowski, M.; Krakowiak, J.; Stangret, J. Hydration of simple amides. FTIR spectra of HDO and theoretical studies. J. Phys. Chem. B 2008, 112, 2483-2493. [CrossRef] [PubMed]

31. Gilli, P.; Bertolasi, V.; Ferretti, V.; Gilli, G. Covalent nature of the strong homonuclear hydrogen bond: Study of the O-H..O system by crystal structure correlation methods. J. Am. Chem. Soc. 1994, 116, 909-915. [CrossRef]

32. Alabugin, I.V.; Manoharan, M.; Peabody, S.; Weinhold, F. Electronic basis of improper hydrogen bonding: A subtle balance of hyperconjugation and rehybridization. J. Am. Chem. Soc. 2003, 125, 5973-5987. [CrossRef] [PubMed]

33. Gilli, P.; Bertolasi, V.; Pretto, L.; Gilli, G. Outline of a transition-state hydrogen-bond theory. J. Mol. Struct. 2006, 790, 40-49. [CrossRef]

34. Pakiari, A.H.; Eskandari, K. The chemical nature of very strong hydrogen bonds in some categories of compounds. J. Mol. Struct. 2006, 759, 51-60. [CrossRef] 
35. Xu, W.; Zhang, R. A theoretical study of hydrated molecular clusters of amines and dicarboxylic acids. J. Chem. Phys. 2013, 139, 53-58. [CrossRef] [PubMed]

36. Esseffar, M.; el Firdoussi, A.; Bouab, W.; Abboud, J.L.M.; Mo, O.; Yanez, M. Combined experimental and theoretical study on hydrogen-bonded complexes between cyclic ketones, lactones, and lactams with 3,4-dinitrophenol. J. Phys. Chem. A 2009, 113, 14711-14717. [CrossRef] [PubMed]

37. El Firdoussi, A.; Esseffar, M.; Bouab, W.; Abboud, J.L.M.; Mo, O.; Yanez, M.; Ruasse, M.F. Density functional theory study of the hydrogen bond interaction between lactones, lactams, and methanol. J. Phys. Chem. A 2005, 109, 9141-9148. [CrossRef] [PubMed]

38. Zhao, H.; Chang, J.; Du, L. Effect of hydrogen bonding on the spectroscopic properties of molecular complexes with aromatic rings as acceptors. Comput. Theor. Chem. 2016, 1084, 126-132. [CrossRef]

39. Zhang, Q.; Du, L. Hydrogen bonding in the carboxylic acid-aldehyde complexes. Comput. Theor. Chem. 2016, 1078, 123-128. [CrossRef]

40. Zhao, H.; Zhang, Q.; Du, L. Hydrogen bonding in cyclic complexes of carboxylic acid-sulfuric acid and their atmospheric implications. RSC Adv. 2016, 6, 71733-71743. [CrossRef]

41. Tang, S.; Zhao, H.; Du, L. Hydrogen bonding in alcohol-ethylene oxide and alcohol-ethylene sulfide complexes. RSC Adv. 2016, 6, 91233-91242. [CrossRef]

42. Du, L.; Kjaergaard, H.G. Fourier transform infrared spectroscopy and theoretical study of dimethylamine dimer in the gas phase. J. Phys. Chem. A 2011, 115, 12097-12104. [CrossRef] [PubMed]

43. Zhao, H.; Tang, S.; Li, S.; Ding, L.; Du, L. Theoretical investigation of the hydrogen bond interactions of methanol and dimethylamine with hydrazone and its derivatives. Struct. Chem. 2016, 27, 1241-1253. [CrossRef]

44. Howard, D.L.; Kjaergaard, H.G. Hydrogen bonding to divalent sulfur. Phys. Chem. Chem. Phys. 2008, 10, 4113-4118. [CrossRef] [PubMed]

45. Dulce, M.; Faria, G.; Teixeira-Dias, J.J.C.; Fausto, R. Hydrogen bonding involving alpha-beta-unsaturated carboxylic esters and substituted phenols: An infrared spectroscopic study. J. Mol. Struct. 1991, 263, 87-94.

46. D'Alva Torres, G.S.F.; Pouchan, C.; Teixeira-Dias, J.J.C.; Fausto, R. Hydrogen bonding between substituted phenols and $\mathrm{CH}_{3} \mathrm{COOCH}_{3}$ or $\mathrm{CH}_{2} \mathrm{ClCOOCH}_{3}$ : An FTIR spectroscopic study. Spectrosc. Lett. 1993, 26, 913-922. [CrossRef]

47. Putz, M.V. Markovian approach of the electron localization functions. Int. J. Quant. Chem. 2005, 105, 1-11. [CrossRef]

48. Matito, E.; Putz, M.V. New link between conceptual density functional theory and electron delocalization. J. Phys. Chem. A 2011, 115, 12459-12462. [CrossRef] [PubMed]

49. Hobza, P.; Havlas, Z. Blue-shifting hydrogen bonds. Chem. Rev. 2000, 100, 4253-4264. [CrossRef] [PubMed]

50. Joseph, J.; Jemmis, E.D. Red-, blue-, or no-shift in hydrogen bonds: A unified explanation. J. Am. Chem. Soc. 2007, 129, 4620-4632. [CrossRef] [PubMed]

51. Van der Veken, B.J.; Herrebout, W.A.; Szostak, R.; Shchepkin, D.N.; Havlas, Z.; Hobza, P. The nature of improper, blue-shifting hydrogen bonding verified experimentally. J. Am. Chem. Soc. 2001, 123, 12290-12293. [CrossRef] [PubMed]

52. Delanoye, S.N.; Herrebout, W.A.; van der Veken, B.J. Blue shifting hydrogen bonding in the complexes of chlorofluoro haloforms with acetone- $d_{6}$ and oxirane- $d_{4}$. J. Am. Chem. Soc. 2002, 124, 11854-11855. [CrossRef] [PubMed]

53. Blanco, S.; Pinacho, P.; López, J.C. Hydrogen-bond cooperativity in formamide2-water: A model for water-mediated interactions. Angew. Chem. Int. Ed. 2016, 55, 1-6. [CrossRef] [PubMed]

54. Mahadevi, A.S.; Sastry, G.N. Cooperativity in noncovalent interactions. Chem. Rev. 2016, 116, $2775-2825$. [CrossRef] [PubMed]

55. Koch, U.; Popelier, P. Characterization of $\mathrm{CHO}$ hydrogen bonds on the basis of the charge density. J. Phys. Chem. 1995, 99, 9747-9754. [CrossRef]

56. Grabowski, S.J. Hydrogen bonding strength-measures based on geometric and topological parameters. J. Phys. Org. Chem. 2004, 17, 18-31. [CrossRef]

57. Popelier, P. Characterization of a dihydrogen bond on the basis of the electron density. J. Phys. Chem. A 1998, 102, 1873-1878. [CrossRef]

58. Su, P.; Li, H. Energy decomposition analysis of covalent bonds and intermolecular interactions. J. Chem. Phys. 2009, 131, 014102. [CrossRef] [PubMed] 
59. Vijay, D.; Sakurai, H.; Subramanian, V.; Sastry, G.N. Where to bind in buckybowls? The dilemma of a metal ion. Phys. Chem. Chem. Phys. 2012, 14, 3057-3065. [CrossRef] [PubMed]

60. Senthilkumar, L.; Ghanty, T.K.; Ghosh, S.K. Electron density and energy decomposition analysis in hydrogen-bonded complexes of azabenzenes with water, acetamide, and thioacetamide. J. Phys. Chem. A 2005, 109, 7575-7582. [CrossRef] [PubMed]

61. Thellamurege, N.; Hirao, H. Water complexes of cytochrome p450: Insights from energy decomposition analysis. Molecules 2013, 18, 6782. [CrossRef] [PubMed]

62. Frisch, M.J.; Trucks, G.W.; Schlegel, H.B.; Scuseria, G.E.; Robb, M.A.; Cheeseman, J.R.; Scalmani, G.; Barone, V.; Mennucci, B.; Petersson, G.A.; et al. Gaussian 09, Revision E.01, Gaussian, Inc.: Wallingford, CT, USA, 2013.

63. Goerigk, L.; Grimme, S. A thorough benchmark of density functional methods for general main group thermochemistry, kinetics, and noncovalent interactions. Phys. Chem. Chem. Phys. 2011, 13, 6670-6688. [CrossRef] [PubMed]

64. Hansen, A.S.; Du, L.; Kjaergaard, H.G. The effect of fluorine substitution in alcohol-amine complexes. Phys. Chem. Chem. Phys. 2014, 16, 22882-22891. [CrossRef] [PubMed]

65. Hansen, A.S.; Du, L.; Kjaergaard, H.G. Positively charged phosphorus as a hydrogen bond acceptor. J. Phys. Chem. Lett. 2014, 5, 4225-4231. [CrossRef] [PubMed]

66. Boys, S.F.; Bernardi, F. The calculation of small molecular interactions by the differences of separate total energies: Some procedures with reduced errors. Mol. Phys. 1970, 19, 553-566. [CrossRef]

67. Dunn, M.E.; Pokon, E.K.; Shields, G.C. Thermodynamics of forming water clusters at various temperatures and pressures by gaussian-2, gaussian-3, complete basis set-QB3, and complete basis set-APNO model chemistries: Implications for atmospheric chemistry. J. Am. Chem. Soc. 2004, 126, 2647-2653. [CrossRef] [PubMed]

68. Feller, D. Application of systematic sequences of wave functions to the water dimer. J. Chem. Phys. 1992, 96, 6104-6114. [CrossRef]

69. Bader, R.F. A quantum theory of molecular structure and its applications. Chem. Rev. 1991, 91, 893-928. [CrossRef]

70. Schmidt, M.W.; Baldridge, K.K.; Boatz, J.A.; Elbert, S.T.; Gordon, M.S.; Jensen, J.H.; Koseki, S.; Matsunaga, N.; Nguyen, K.A.; Su, S.; et al. General atomic and molecular electronic structure system. J. Comput. Chem. 1993, 14, 1347-1363. [CrossRef] 